\title{
Synthesis of Cyano Cyclic Olefins through Ring-Closing Metathesis
}

\author{
Thl Young Choi, Kyoung Hee Byoun, ${ }^{\star}$ Myung Hee Jung, Hee-Jeong Lim, and Hyo Won Lee
}

\author{
Korea Research Institute of Chemical Techolog, Daejeon 305-600, Korea \\ -Department of Chemistry; Chungbut National Lniversitw; Cheongiu, Chungbuk 361-763, Korea \\ Recerved July 12,2004
}

Key Words : Ring-closing metathesis. Microwave irradiation. Cyano cyclic olefins

Ring-closing metathesis has become a very powerful. versatile. and widely used method for the construction of cyclic ring systems in organic synthesis. 'The superior reactivity of Grubbs second generation catalyst 1 . which has air-stability and thermal stability. is very important for the formation of tri- and tetra-substituted olefins having electron withdrawing groups. Recently: Weinreb. ${ }^{\text {a }}$ Salim and Rutjes $^{2 c}$ reported on the formation of carbocyclic and heterocyclic olefin by ring-closing metathesis of halogen $(F$. $\mathrm{Cl}, \mathrm{CF}_{3}$ ) substituted olefins. Literature survey reveals that most of bisteminal olefins with electron withdrawing groups such as $\mathrm{CO}_{2} \mathrm{Et}$. $\mathrm{Br}$. and $\mathrm{CN}$ resulted in little to no yield of the RCM product under the condition of using the Grubbs first generation catalyst. ${ }^{3}$ but the microwave irradiation on olefin with carboxymethỵl substituent $\left(\mathrm{CO}_{2} \mathrm{Me}\right)$ provided the desired product. ${ }^{+}$

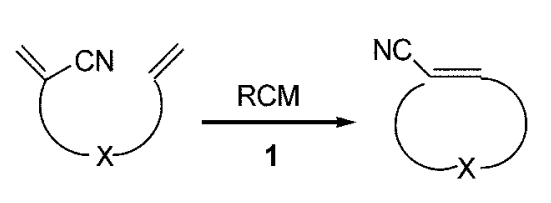

$X=\mathrm{CR}_{2}, \mathrm{NR}, \mathrm{O}$<smiles></smiles>

Grubbs catalyst 1
Scheme 1. Ring-Closing Metathesis (RCM) Reaction of Cvano Bisolefins.
As part of synthesis of a drug against Alzheimer disease. we became interested in the introduction of a nitrile group to huperzine B analog system. Monocyclic olefins with cyano group were prepared. Alkylations with 2-(bromoethyl)acrylonitrile were carried out to obtain several allylated substrates 3a-e from the carbon and heteroatom nucleophiles $2 \mathbf{a e}^{7-9}$ in DMF in the presence of $\mathrm{NaH}$ as base. The RCM reaction of the bisterminal olefins 3a-e with a cyanide group has been explored for a variety of substrates. and some of the results are shown in Table 1 . The substrates 3a-e reacted smoothly and furnished the olefinic cyanides containing six to seven membered cycles in high yields (Entry l-5). With successful outcome for the preparation of monocyclic cyanoolefins. we applied this method to the synthesis of tricyclic șystem of huperzine B analog (Scheme 3). ${ }^{10}$ Subjection of olefinic intermediate 6 to the standard condition ( 5 mol \% catalyst 1 and $3 \times 10^{-3} \mathrm{M}$ substrate in $\mathrm{CH}_{2} \mathrm{Cl}_{2}$ ) provided a poor yield $(5 \%)$ of cyclized product $6 \mathrm{a}$ despite the complete consumption of starting material. Thus. the reaction was performed at elevated temperature of $100^{\circ} \mathrm{C}$ under microwave irradiation with $5 \mathrm{~mol} \%$ catalytic amount using the concentration of $0.05 \mathrm{M}$ of the substrate in $\mathrm{CH}_{2} \mathrm{Cl}_{2}$. After 4 min of the irradiation. the RCM reaction provided an improved yield of $\mathbf{6 a}$ with no sign of other undesired reactions based on the recovered starting material.

In conclusion. we have revealed an example of the ring-<smiles>[R]C([R])C=C</smiles><smiles>C=C(C#N)CBr</smiles>

$2 a \cdot e$<smiles>[R]C([Y])CC(=C)CN</smiles>

3a-e

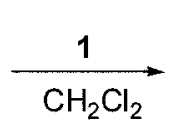<smiles>[R]C1CC2CCC(C#N)CC1C2</smiles>

4a-e

$\mathrm{R}_{1}=\mathrm{Bn}$ or $\mathrm{H}, \mathrm{n}=1-2$

$\mathrm{X}=\mathrm{NBz}, \mathrm{NTs}, \mathrm{O}, \mathrm{C}\left(\mathrm{CO}_{2} \mathrm{Et}\right)_{2}$

Scheme 2. RCM Reaction of Monocyclic Cyanoalkenes.

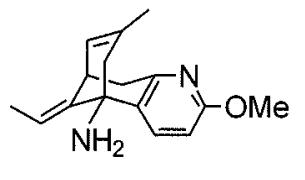

5

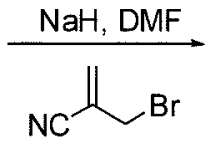

$\mathrm{NC} \mathrm{Br}$
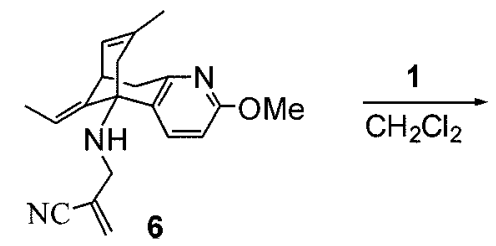

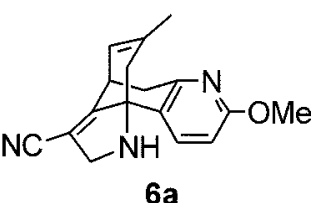

$6 a$

Scheme 3. RCM Reaction for A Cyano Derivative of Huperzine B. 
Table 1. Ring-Closing Metathesis Reactions of Vinyl Nitrile ${ }^{11}$

Entry

"The yield in parentheses is the yield based on the recovered starting material.

closing metathesis reaction for cyano cyclic olefins. Also we proved the RCM reaction can be applied to the construction of complicated structure of tribicyclic huperzine B analog with help of the irradiation of microwave.

Acknowledgement. This work was supported by the Ministry of Science Technology Grant (KK-0401-D1).

\section{References}

1. For recent metathesis reviews. see: (a) Grubbs. R. H: Chang. S.
Tetrahedron 1998. 5t, $4113-4450$. (b) Armstrong. S. K. J. Chem. Soc. Porkin Trans. I 1998. 371-388. (c) Fürstner. A. Angen: Chent. Imt. Ed. $2000.39 .3012-3043$.

2. (a) Chao. W.: Weinreb. S. M. Org. Lett. 2003. 5. 2505-2507. (b) Salim. S. S.: Bellingham. R. K.; Satcharoen, V.: Brown. R. C. D. Org. Lett. 2003. 5. 3403-3406. (c) Matteis, V. D.; van Delft. F. L: de Gelder. R.: Tiebes, J.: Rutjes. F. P. J. T. Tetrahedron Lett. 2004. 45. 959-963.

3. (a) Crowe. W. E.: Goldberg. D. R. J.Am. Chem. So. 1995. 117 . 5162-5163. (b) Kirkland. T. A.: Grubbs. R. H. J. Org Chent. 1997. 62. $7310-7318$. (c) Gessler, S.; Randl. S.; Blechert, S Tetrahedron Lett 2000, 41.9973-9976. (d) Basu, K.: Cabral. J. A.; Pacuette, L. A. Tetrahedron Lett 2002. 43. 5453-5456. e) Clercq. B. D.: Verpoot. F. Tetrahedron Lett. 2002. H1. 9101-9104. (f) Demel. S.: Riegler. S.: Wewerka. K.: Schoefberger. W.: Slugowc. C.: Stelzer. F. Inorg Chim. Acta 2003. 3+5. 363-366.

4. (a) Yang, C.: Murray, W. V. Wilson, L. J. Tetrohedron Lett. 2003. 14. 1783-1786. (b) Balan. D: Adolfsson. H. Tetrahedron Lett. 2004. $45,3089-3092$.

5. Procedure for ring closing metathesis of 6 to give $6 \mathrm{a}$. A solution of the vinyl nitrile $6(0.012 \mathrm{mmol})$ and catalyst $1(5 \mathrm{~mol} 9.0)$ in $\mathrm{CH}_{2} \mathrm{Cl}_{2}(2.5 \mathrm{~mL})$ was microwave irradiated in a sealed tube for 4 min at $100{ }^{\circ} \mathrm{C}$ using an Personal Chemistry Optimizer and Creator. The solvent was removed in vacto and the residue was purified by column chromatography ( $35^{\circ}$ o ethyl acetate in hexane) to provide 6a: IR ( $v_{\max }$. neat) 2925. 2854. 2220. 1597. 1475. 1257 $\mathrm{cm}^{-1},{ }_{1}^{1} \mathrm{HNMR}(300 \mathrm{MHz}, \mathrm{CDCl}) \delta 7.52(\mathrm{~d}, j=8.4 \mathrm{~Hz}, \mathrm{lH}), 6.62$ $(\mathrm{d} . J=8.4 \mathrm{~Hz}, \mathrm{lH}) .5 .50$ (brs. $1 \mathrm{H}) .4 .05,3.99(\mathrm{ABq} . J=13.8 \mathrm{~Hz}$. $2 \mathrm{H}) .3 .89(\mathrm{~s}, 3 \mathrm{H}) .3 .77$ (brs, lH), $3.13(\mathrm{dd}, J=17.2 .4 .8 \mathrm{~Hz} .1 \mathrm{H})$. $3.06(\mathrm{dd} . J=17.2 .1 .8 \mathrm{~Hz} .1 \mathrm{H}) .2 .64(\mathrm{~d} . J=16.8 \mathrm{~Hz} .1 \mathrm{H}) .2 .30$ (d. $J=16.8 \mathrm{~Hz} . \mathrm{IH}) \cdot 1.56(\mathrm{~s} .3 \mathrm{H}):{ }^{13} \mathrm{C} \mathrm{NMR}(125 \mathrm{MHz} . \mathrm{CDCl}) \delta$ 164.2. 163.7. 151.5. 136.3. 135.0. 131.1. 124.2. 115.1. 110.4. 99.3, 69.8. 55.0. 54.1, 49.0, 41.0. 34.9.23.4, HRMS (EI) Caled for $\mathrm{C}_{17}: \mathrm{H}_{1}: \mathrm{N}_{3} \mathrm{O}\left(\mathrm{M}^{-}\right) 279.1372$. found 279.1372 .

6. Csuk. R; Schmid, P. Tetrahedron Lett. 1996. 37,9759-9776.

7. Katritzky. A. R.: Ignatchenko. A. V.: Lang. H. J. Org. Chem. 1995. $60.4002-4005$

8. McCluskey. A.: Mayer. D. M.: Young. D. T. Tetrahedhon Lett. $1997.38,5217-5218$.

9. Veenstra, S. J:- Schmid, P. Tetrahedhon Lett 1997.38.997-1000.

10. Lee. I.-Y. C.: Hong. J. Y.; Jung. M. H.: Lee, H. W. Tetrahedron Lett. 2004. 45. 287-289.

11. Typical procedure for RCM of vinyl nitrile: To a solution of the vinyl nitrile $(0.102 \mathrm{mmol})$ in dry $\mathrm{CH}_{2} \mathrm{Cl}_{2}(34.0 \mathrm{~mL})$ was added the Grubbs second generation catalyst $(10 \mathrm{~mol} \%)$. The reaction misture was stirred for $1-2 \mathrm{~h}$ at $60^{\circ} \mathrm{C}$. The solvent was removed in vacuo and the residue was purified by column chromatography $\left(200^{\circ}\right.$ e ethyl acetate in hexane) to yield the product. 